\title{
Factors influencing the uptake of ${ }^{18} \mathrm{~F}$-Fluoroestradiol (FES) in patients with estrogen receptor positive (ER+) breast cancer
}

\author{
Lanell M Peterson, Brenda F Kurland, Jeanne M Link, Erin K Schubert, Svetlana Stekhova, \\ Hannah M Linden, and David A Mankoff \\ Department of Radiology, Department of Medical Oncology-University of Washington Medical \\ Center/Seattle Cancer Care Alliance, Fred Hutchinson Cancer Research Center, Seattle WA
}

\begin{abstract}
Introduction- ${ }^{18}$ F-Fluoroestradiol (FES) PET imaging provides a non-invasive method to measure estrogen receptor (ER) expression in tumors. Assessment of factors that could affect the quantitative level of FES uptake is important as part of the validation of FES PET for evaluating regional ER expression in breast cancer.
\end{abstract}

Methods-This study examines FES uptake in tumors from 312 FES PET scans (239 patients) with documented ER+ primary breast cancer. FES uptake was compared to clinical and laboratory data; treatment prior to or at time of scan; and properties of FES and its metabolism and transport. Linear mixed models were used to explore univariate, threshold-based, and multivariate associations.

Results-Sex-hormone binding globulin (SHBG) was inversely associated with FES SUV. Average FES uptake did not differ by levels of plasma estradiol, age, or rate of FES metabolism. FES tumor uptake was greater for patients with a higher body mass index (BMI), but this effect did not persist when SUV was corrected for lean body mass (LBM). In multivariate analysis, only plasma SHBG binding was an independent predictor of LBM-adjusted FES SUV.

Conclusions-Calculation of FES SUV, possibly adjusted for lean body mass, should be sufficient to assess FES uptake for the purpose of inferring ER expression. Pre-menopausal estradiol levels do not appear to interfere with FES uptake. The availability and binding properties of SHBG influence FES uptake and should be measured. Specific activity did not have a clear influence on FES uptake, except perhaps at higher injected mass $/ \mathrm{kg}$. These results suggest that FES imaging protocols may be simplified without sacrificing the validity of the results.

\section{Keywords}

FES PET; breast cancer; SHBG; specific activity

\footnotetext{
(C) 2011 Elsevier Inc. All rights reserved.

Corresponding Author: David A. Mankoff, MD, PhD, Radiology (Nuclear Medicine), Box 356113, University of Washington Medical Center, 1959 NE Pacific Street, Seattle, WA, 98195, Phone: 206-288-2173, Fax: 206-288-6965, dam@u.washington.edu.

Publisher's Disclaimer: This is a PDF file of an unedited manuscript that has been accepted for publication. As a service to our customers we are providing this early version of the manuscript. The manuscript will undergo copyediting, typesetting, and review of the resulting proof before it is published in its final citable form. Please note that during the production process errors may be discovered which could affect the content, and all legal disclaimers that apply to the journal pertain.
} 


\section{Introduction}

Positron Emission Tomography (PET) using 16 a-[F-18]-fluoro-17- $\beta$-estradiol (FES) imaging is a method for imaging functional ER expression in-vivo, and may be used as a quantitative measure of estrogen receptor (ER) expression in breast cancer [1, 2]. FES PET may offer complementary advantages to in vitro assay of biopsy material, including the measurement of ER binding, identification of heterogeneous expression over the entire burden of disease, and measurement of the pharmacodynamic effect of ER-directed therapy [3]. The factors influencing FES uptake, however, are incompletely understood.

Determining the factors that affect FES uptake, other than the desired dependency on ER expression levels, contributes to further understanding of this novel diagnostic tool and its use to measure regional ER expression.

Serum estrogen levels vary with menopausal status and drug therapy. Aromatase inhibitors reduce serum estrogen levels, and tamoxifen is an estrogen receptor blocking agent with variable impact on serum estrogen levels [4-6]. The influence of circulating estrogens in the physiologic range in humans on FES tumor uptake is unknown. Some prior reports have hypothesized that competition with circulating estrogens in pre-menopausal patients might lead to decreased FES uptake [7, 8].

FES is metabolized rapidly in vivo in both animals and humans $[9,10]$. In humans, only about $20 \%$ of circulating radioactivity in the plasma is in the form of non-metabolized FES at 20 minutes after injection. The rate of FES metabolism varies somewhat between patients and may affect the availability of FES in the blood and thus the level of uptake in tumors [10].

In the blood, estrogens are transported by and bound tightly to the sex-steroid binding protein (also known as sex hormone binding globulin (SHBG)), which affects their transport and delivery [11]. Kiesewetter showed that FES binding to SHBG is similar to that for estradiol [12]. Tewson, et al. showed that approximately $45 \%$ of FES in circulating plasma is bound to SHBG, but varied between patients and was dependent on the level of SHBG in the plasma [13]. In mature rat hepatocytes, Jonson et al, [14] postulated that SHBG may potentiate the ER-mediated uptake of FES in ER+ tumors by selectively protecting the ligand from metabolism and ensuring its delivery to receptor-containing cells, and suggested that SHBG binding was necessary for an effective PET ER imaging agent. On the other hand, the "free hormone hypothesis" suggests that, like estradiol, FES bound to SHBG might be less available to tissue and thus less likely to reach the estrogen receptors [11], resulting in lower FES uptake.

Prior studies have suggested that high FES specific activity measured at injection $\left(\mathrm{SA}_{\text {inj }}\right)$, and thus low injected mass, is necessary to visualize and quantify ER concentration without competition from "cold" estrogens [15]. While a limiting value of $37000 \mathrm{GBq} / \mathrm{mMol}(1000$ $\mathrm{Ci} / \mathrm{mMol}$ ) has been suggested as a lower limit for acceptable $\mathrm{SA}_{\mathrm{inj}}$, this value has not previously been tested in patients. The limits for acceptable $\mathrm{SA}_{\text {inj }}$ have important implications for FES quality assurance and for the ability to image multiple patients from a single FES production run without reducing the value of the image data. 
The purpose of this study was three-fold: 1) to determine if patient factors, such as age, weight, menopausal status, BMI, serum estradiol levels, and serum SHBG, affect the level of FES uptake; 2) to examine the effect specific activity has on FES uptake; 3 ) to determine the effect of FES metabolism and protein binding on uptake. We would expect that low serum estradiol levels, low SHBG levels and binding, and high specific activity would all predict higher FES uptake. Understanding the factors that affect FES uptake could lead to more streamlined imaging protocols.

\section{Methods}

\section{Patients}

From 1/96 to 11/06, 391 FES scans were performed at the University of Washington Medical Center. The patients were enrolled through one of several protocols at our center to assess FES uptake and metabolism, the heterogeneity of FES uptake in patients with advanced breast cancer, the correlation of FES uptake to in vitro assay of ER, and change in FES uptake during hormonal therapy. All of the patients had met the eligibility requirements of one of the approved protocols from Radioactive Drug Research Committee (RDRC) and University of Washington Human Subjects and signed informed consent.

For this report, from patients imaged with FES at our center, we selected patients who had a documented ER+ primary breast cancer, with at least one disease site greater than $1.5 \mathrm{~cm}$ to avoid severe partial volume effects, and were not taking ER blocking agents such as tamoxifen or fulvestrant for at least 6 weeks prior to scanning. Multiple scans for the same patient were included. Of the $391 \mathrm{FES}$ scans performed, 312 met these criteria. The exclusions were due to no visible viable tumor $(n=35), E R-$ primary disease $(n=11)$, patient on tamoxifen or fulvestrant at the time of the study $(n=29)$, or technical problems $(n=4)$. The remaining 312 studies of 239 patients were analyzed for this report. Of the 51 patients with multiple scans $15 \%(36 / 239)$ had 2 scans, and 6\% (15/239) had 3 or more scans,.

\section{FES synthesis}

The synthesis procedure 16a-[F-18]-fluoro-17ß-estradiol (FES) follows that reported by Lim et al and modified by Romer et al [13, 16, 17]. Reagents and solvents for synthesis and purification were obtained from ABX Biochemicals, Sigma Aldrich Chemical Co., Mallinckrodt Baker, or from USP suppliers and were used without further purification unless otherwise noted. ${ }^{18} \mathrm{~F}$ was produced using either a Siemens Eclipse or a Scanditronix MC-50 cyclotron. Quality control tests were performed immediately following each synthesis to evaluate radiochemical and chemical purity and to calculate specific activity of each dose. Prior to May of $2000(n=45)$, the specific activity of each dose was measured using HPLC analysis and UV detection and are not used in this analysis. After May 2000, $(\mathrm{n}=267)$, the analysis was performed with HPLC-MS (HPLC- Mass Spectrometry) (Waters 2690 and MicroMass ZMD (ES $\left.{ }^{-}\right)$). Specific activity was recorded as $\mathrm{GBq} / \mathrm{mMol}(\mathrm{Ci} / \mathrm{mMol})$ at the time of injection. A typical injection of FES consisted of approximately $185 \mathrm{MBq}(5.0$ $\mathrm{mCi}$ ) (range 103.6-296 MBq (2.8-8.0 mCi)) of radiopharmaceutical in $20 \mathrm{~mL}$ of isotonic phosphate buffered saline containing less than $15 \%$ of ethanol by volume. The mass injected per unit patient weight $(\mu \mathrm{mole} / \mathrm{kg})$ was also recorded. 


\section{PET imaging}

All imaging was performed on a GE Advance tomograph (Waukesah, WI). The protocol for PET imaging has been previously described $[10,18]$. Briefly, following an attenuation scan of 20-25 minutes, FES was injected over 2 minutes. Sixty minutes of dynamic imaging over the main area of interest was followed by a five field-of-view (FOV) sweep to further assess the extent of disease.

\section{Blood Analysis}

Whenever possible, a second venous access site was used for blood sampling during the scan for measures of FES metabolism and SHBG binding.

The methods for processing the plasma used for HPLC metabolite analysis to determine blood radioactivity present as FES versus labeled metabolites (\%FES) have been previously published [10]. Briefly, for HPLC analysis, a $50 \mu \mathrm{l}$ sample of filtered plasma collected at 5, 20 , or 60 minutes post injection was injected onto a $4.6 \times 250 \mathrm{~mm}(10 \mu \mathrm{m}) \mathrm{C}-18$ column (Econosil Alltech, Deerfield IL). The column eluant fractions were collected and counted in the same gamma counter (Packard Cobra, Meridian, CT) used for the blood samples. The blood samples collected at 20 minutes after injection were used in this analysis.

The methods for SHBG analysis at the time of the study have also been previous reported $[13,19]$. A plasma sample collected prior to injection was spiked with a small quantity $((\sim 0.074 \mathrm{MBq}(\sim 2 \mu \mathrm{Ci}))$ of FES. Four hundred $\mu \mathrm{L}$ of the plasma was placed into each of 2 tubes. Non-radioactive dihydrotestosterone (DHT) (Steraloids Inc, Wilton NH) $0.75 \mathrm{ng} / 100$ $\mu \mathrm{L}$, was added to one of the tubes. The tubes were incubated then cooled and an equal volume of saturated ammonium sulfate solution was added. The tubes were centrifuged and the supernatant was decanted into a separate tube. An equal volume of water was added to the tube containing the pellet. Samples were then counted in the same well detector gamma counter as all other samples. Specific binding of the tracer was calculated as:

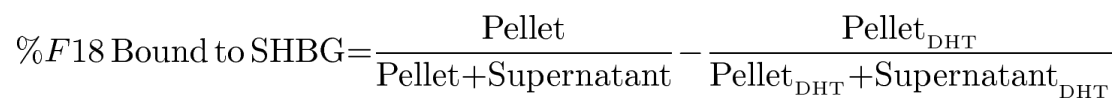

Pellet and supernatant refer to the background corrected counts in those fractions and the DHT subscript refers to the sample to which an excess of DHT was added to displace the FES.

\section{Additional clinical and laboratory measures}

For most patients, serum was collected prior to FES injection, was frozen and then sent for assay of plasma SHBG levels (nM) with dual antibody immunoassay (ARUP laboratories ${ }^{\mathrm{TM}}$ operating procedure CORE-99375 (Salt Lake City, Utah).

Blood samples, taken just prior to injection, were also collected and sent to Laboratory Services at the University of Washington for standard clinical assays of estradiol, testosterone and albumin. Estradiol detectable limits by this assay were $20 \mathrm{pg} / \mathrm{mL}$ and testosterone detectable limits were $0.5 \mathrm{ng} / \mathrm{mL}$ or $0.2 \mathrm{ng} / \mathrm{mL}$ as reported by Laboratory 
Services. Estradiol levels below $30 \mathrm{pg} / \mathrm{mL}$ were considered to be postmenopausal per guidance of the UWMC laboratory. Albumin was reported in g/dL (normal range 3.5-5.2 g/ $\mathrm{dL})$.

\section{Image analysis}

As in earlier studies $[2,10,18]$, the primary FES uptake measure used in this analysis was the mean SUV of peak ROIs on summed images over the last 30 minutes of imaging (30-60 minutes). ROIs were placed using the aid of correlative anatomic imaging (mammogram, ultrasound, or CT), the PET transmission scan, and/or FDG-PET images, as needed. Square ROIs of 16 pixels each $(\sim 1.5 \mathrm{~cm})$ were placed over the tumor site on three adjacent imaging planes. SUV was calculated by the commonly used formula: SUV = tissue activity $(\mu \mathrm{Ci} / \mathrm{mL}) /($ injected dose/patient weight) $(\mathrm{mCi} / \mathrm{Kg})$. For patients with more than 1 tumor visible in the dynamic field-of-view, the mean SUVs for up to 3 tumors was averaged. To avoid the confounding effects of severe partial volume effects, only lesions with diameters of $1.5 \mathrm{~cm}$ or greater were included.

An alternative measure of FES uptake was analyzed to further examine the association between FES uptake and patient weight. SUV corrected for lean body mass, $S_{U V} V_{L B M}$, substituted lean body mass (LBM) for patient weight in calculating SUV, with LBM calculated using the James method [20].

\section{Statistical analysis}

Our overall goal was to identify factors that affect FES uptake besides the level of ER expression. Ideally this would also consider an independent measure of ER expression, such as assay of biopsy material, in the analysis. However, biopsy of all lesions in the large population of patients studied, most with multiple sites of metastatic disease, was neither practical nor ethical. We instead tested for an association of these factors with FES uptake level in a cohort of patients documented as having ER-expressing tumors. Although ER expression levels varied across patients, the large number of patients studied permits fairly robust tests to screen for other factors that might affect FES uptake. Few, if any of the factors tested, for example specific activity and FES metabolism, have a known or suspected independent association with ER expression. Some factors, for example, menopausal status, could have a minor association with ER expression levels; however, selecting only patients with ER-expressing tumors mitigated the possible effect of such associations.

Associations between factors and FES SUV uptake were first explored through scatterplots and smoothed local linear polynomial (LOWESS) fits [21]. Following suitable transformations to satisfy linear model assumptions, univariate and multivariate linear mixed models were fitted with random intercepts to account for patient-level clustering. Potential linear, non-linear, and threshold-based patterns were also explored based on mechanisms proposed in the FES literature as described in the Introduction.

To address the relationship between FES specific activity measured at injection $\left(\mathrm{SA}_{\mathrm{inj}}\right)$ and FES uptake at low values of $S A_{\text {inj }}$, we examined a subset of scans with low $\mathrm{SA}_{\text {inj }}$ ( $\triangle 200 \mathrm{Ci}$ / mMol, based upon prior reports [7, 8]) separately. A post hoc power calculation [22] was used to estimate the strength of association that could be observed with 93 scans conducted 
with $\mathrm{SA}_{\text {inj }} \leq 44,400 \mathrm{GBq} / \mathrm{mMol}$ ( $\leq 200 \mathrm{Ci} / \mathrm{mMol}$ ). Observed values for the subset with low $\mathrm{SA}_{\mathrm{inj}}$ and the full sample were used to choose appropriate transformations, and to estimate standard deviations for $\mathrm{SA}_{\text {inj }}$ and $\log (\mathrm{SUV})$. Observed standard deviations were used to interpret correlation coefficients as slopes, using the easily derived relationship between correlation and univariate linear regression [23]. Fisher's $\mathrm{Z}$ transformation was used to normalize the sample correlation coefficient, so that a sample size calculation for the normal distribution could approximate the minimum detectable effect size for the association between $\mathrm{SA}_{\text {inj }}$ and FES SUV. For a linear model with $\mathrm{SA}_{\text {inj }}$ (standard deviation $=10,360$ $\mathrm{GBq} / \mathrm{mMol}(280 \mathrm{Ci} / \mathrm{mMol}))$ predicting $\log (\mathrm{FES} \mathrm{SUV})($ standard deviation $=0.66)$, a correlation of 0.28 would correspond to a $7 \%$ difference in SUV for scans similar for a $3,700 \mathrm{GBq} / \mathrm{mMol}(100 \mathrm{Ci} / \mathrm{mMol})$ difference in specific activity, and a $39 \%$ difference in SUV for a $18,500 \mathrm{GBq} / \mathrm{mMol}\left(500 \mathrm{Ci} / \mathrm{mMol}\right.$ ) difference in $\mathrm{SA}_{\text {inj }}$ (within the $0-44,400 \mathrm{GBq} /$ $\mathrm{mMol}(0-1200 \mathrm{Ci} / \mathrm{mMol})$ range for $\left.\mathrm{SA}_{\text {inj }}\right)$. Similarly, a correlation of 0.32 corresponds to SUV differences of $8 \%$ and $46 \%$ for a $3700 \mathrm{GBq} / \mathrm{mMol}(100 \mathrm{Ci} / \mathrm{mMol})$ and a $18,500 \mathrm{GBq} /$ $\mathrm{mMol}(500 \mathrm{Ci} / \mathrm{mMol})$ point difference in $\mathrm{SA}_{\text {inj. }}$. For two-sided tests at the $\mathrm{a}=.05$ level, a sample of 93 scans would have $80 \%$ power to detect a correlation of 0.28 , and $90 \%$ power to detect a correlation of 0.32 .

Three hundred twelve studies were included in the initial analyses. A sensitivity analysis excluded scans with a least one known lesion that was qualitatively ER- by FES imaging $(\mathrm{n}=80)$ to account for the possibility of loss of ER expression with recurrence and metastasis [24], since ER+ status was pathologically confirmed only for the primary breast tumor at the time of initial diagnosis for most patients. The sensitivity analysis also excluded patients who were on chemotherapy at the time of the scan ( $\mathrm{n}=50$, including 21 who also had at least one qualitatively ER- lesion by FES imaging), due to the known effects of chemotherapy on tumor viability.

\section{Results}

Table 1 summarizes the characteristics of the 312 FES studies analyzed for 239 breast cancer patients with previously documented ER+ primary tumors. Nearly all scans (298/312) were conducted in patients with advanced stage breast cancer (Stage III or IV). Two hundred ninety-eight of the scans were conducted on female patients $(67 \%$ postmenopausal), and 14 on males. The average age at scan time was 54 years (range 2388). The weight range was $46-156 \mathrm{~kg}$ (mean $74 \mathrm{~kg}$ ), and the average body mass index (BMI) was 27 (range 18-55). Patients' serum estradiol levels were $30 \mathrm{pg} / \mathrm{ml}$ or greater for $27 \%(82 / 309)$ of scans, and testosterone levels were $0.5 \mathrm{ng} / \mathrm{ml}$ or greater for $25 \%(75 / 296)$. Excluding scans where therapy history was uncertain, 51\% (155/301) were performed in patients with remote prior exposure to tamoxifen, 57\% (170/297) with remote prior radiation therapy, and 74\% (220/298) with remote prior chemotherapy.

The average FES dose injected was $185 \mathrm{MBq}(5.0 \mathrm{mCi}$ ) with a range of 103.6-296 MBq (2.8-8.0 mCi ). Radiochemical purity of the FES was measured and approved for each production run. Specific activity was available for 267 scans with a mean of $156,917 \mathrm{GBq} /$ $\mathrm{mMol}(4,241 \mathrm{Ci} / \mathrm{mMol})($ range $7,992-1,671,216 \mathrm{GBq} / \mathrm{mMol}(216-45,168 \mathrm{Ci} / \mathrm{mMol}))$ at time of injection. 
The average SUV was 2.1 (range 0.13-9.6). For 35\% of scans, the SUV was of a single tumor in the dynamic field-of-view. For other scans, reported SUV was the average of two $(22 \%)$ or three $(43 \%)$ tumors. Natural log transformations of SUV values, BMI, specific activity, and nmol of FES injected/kg were performed to satisfy linear model assumptions.

The left side of Table 2 summarizes univariate associations between average FES SUV and patient characteristics (age, sex, menopausal status, disease stage, tumor HER2-neu status, any FES negative sites, BMI), prior treatment (prior chemotherapy, radiation, or tamoxifen use and concurrent chemotherapy), blood assays (serum estradiol, testosterone, albumin, serum SHBG, rate of FES metabolism (\% of plasma activity present as FES at 20 minutes post injection)), and FES characteristics for imaging (dose, $\mathrm{SA}_{\text {inj }}$, nmol of FES injected $/ \mathrm{kg}$, fractional binding of SHBG to FES). To interpret regression parameters with $\log$ (FES SUV) as the outcome, results are presented as the ratio of FES SUV for values of the predictor variable that are one unit (or another measure chosen to be approximately the difference between the third or first quartile and the median) apart.

Concurrent chemotherapy and patients with one or more qualitatively negative lesions were each associated with lower FES uptake ( $\mathrm{p}=0.02$ and $\mathrm{p}=<0.001$ respectively). A sensitivity analysis (described above) repeated the univariate analysis excluding patients with negative FES PET scans and/or concurrent chemotherapy, and is described on the right side of Table 2.

Several factors hypothesized to affect FES uptake did not appear to have a significant impact on uptake, within the observed ranges of these variables and FES uptake. Figure 1A shows FES SUV by values of circulating estradiol. Although it appears that FES SUV is slightly higher for moderate estradiol values (20-30 pg/mL), this is not supported by hypothesized relationships or by quantitative findings. Differences in average FES SUV were not observed for estradiol levels above versus below $30 \mathrm{pg} / \mathrm{mL}$, a cutoff point used to indicate post-menopausal levels (comparing left and right sides of dashed line in Figure 1A, $\mathrm{p}=0.58$ and $\mathrm{p}=0.47$ for univariate and sensitivity analysis respectively). Furthermore, no relationship was found between estradiol levels and FES SUV for the 82 studies with plasma estradiol $\geq 30 \mathrm{pg} / \mathrm{mL}(110 \mathrm{fmol} / \mathrm{mL}$ ) (within right side of dashed line in Figure $1 \mathrm{~A}, \mathrm{p}=$ 0.26). Similarly, FES uptake was not related to testosterone and albumin levels: the "borderline significant" univariate result (17\% higher expected FES SUV for testosterone $\geq$ $0.5 \mathrm{ng} / \mathrm{mL}, \mathrm{p}=0.05$ ) was not reinforced by the sensitivity analysis ( $7 \%$ lower SUV, $\mathrm{p}=0.44$ ). FES uptake showed no relationship to the rate of FES metabolism (fraction of total activity present as FES at 20 minutes) $(\mathrm{p}=0.19)$. Age, sex, disease stage, and tumor HER2-neu status -- prognostic and predictive factors for disease outcomes in patients with ER+ primary breast cancer -- did not have a significant relationship with FES uptake in this analysis (Table 2).

The plasma levels of SHBG and fractional FES binding to SHBG were both associated with FES uptake, with higher SHBG (nM) and SHBG percent binding associated with lower FES SUV ( $p<0.001$ ). For example, a patient with an observed SHBG of $31 \mathrm{nM}$ (near the 25th percentile) and FES SUV of 1.89 would be expected to have an FES SUV of 1.57 (17\% lower) with SHBG of $72 \mathrm{nM}$ (near the 75th percentile). In the sensitivity analysis, the 
correlation between plasma levels of SHBG (nM) and FES uptake was of lower magnitude, but still significant $(\mathrm{p}=0.009)$. Figure $1 \mathrm{~B}$ shows the negative trend of SHBG $(\mathrm{nM})$ with FES uptake.

Analyzing the effect of specific activity by considering the FES injected molar dose/kg provides a measure of the competition of "cold" FES with radioactive FES for binding to ER. Injected FES mass per kg patient weight did not appear to have a statistically significant negative relationship with FES uptake, (3\% lower SUV expected if injected FES mass $/ \mathrm{kg}$ was doubled, $\mathrm{p}=0.20$, Table 2 ). In the sensitivity analysis, the effect was greater, a $5 \%$ lower SUV if injected FES mass $/ \mathrm{kg}$ was doubled ( $\mathrm{p}=0.16$ ). In the LOWESS fit (Figure 1C) there appeared to be no relationship for injected FES mass lower than approximately $0.2 \mathrm{nmol} / \mathrm{kg}$ and a slight downward slope for higher injected mass per kg. These findings suggest that the exogenous dose of FES does not saturate ER. Although a small effect of injected mass on FES uptake at low $\mathrm{SA}_{\text {inj }}$ values cannot be completely excluded, the magnitude of this effect is, at worst case, small.

Specific activity at injection $\left(\mathrm{SA}_{\mathrm{inj}}\right)$ did not have a significant association with FES uptake in either the full univariate or sensitivity analysis ( $p=0.49$ and 0.34 respectively, Table 2 ).

The scatterplot and LOWESS fit (Figure 2A) suggest a slight increase in FES SUV over the range of values between 5,550 and 44,400 $\mathrm{Gbq} / \mathrm{mMol}$ (between 150 and $1200 \mathrm{Ci} / \mathrm{mMol}$ ). With 93 scans of $\mathrm{SA}_{\text {inj }} \leq 44,400 \mathrm{GBq} / \mathrm{mMol}\left((\leq 200 \mathrm{Ci} / \mathrm{mMol})\right.$ ( 73 of which had SA $\mathrm{A}_{\text {inj }}$ $\leq 37,000 \mathrm{GBq} / \mathrm{mMol}(\leq 1000 \mathrm{Ci} / \mathrm{mMol})$ ) the log transformation of SA was not required to fit a linear mixed model predicting $\log$ (FES SUV) (Figure 2B). The model predicted that a 100 $\mathrm{Ci} / \mathrm{mMol}$ increment in $\mathrm{SA}_{\text {inj }}$ (within the range of 4,440-44,400 GBq/mMol (120-1200 Ci/ $\mathrm{mMol})$ ) would be associated with a $2 \%$ higher FES SUV, but the effect was not statistically significant $(\mathrm{p}=0.49)$. Recall that for a $3,700 \mathrm{GBq} / \mathrm{mMol}(100 \mathrm{Ci} / \mathrm{mMol})$ difference in $\mathrm{SA}_{\mathrm{inj}}$, we estimated $80 \%$ power to detect a difference of $7 \%$ in expected FES SUV, and $90 \%$ power to detect a difference of $8 \%$.

A significant correlation was found between BMI and FES uptake $(\mathrm{p}<0.001)$ for both the univariate and sensitivity analyses. In the univariate analysis FES SUV would be expected to be $11 \%$ higher for a BMI that was $15 \%$ higher. In the sensitivity analysis, the relationship was somewhat stronger with the SUV expected to be $14 \%$ higher for a $15 \%$ higher BMI. Figure 3A shows a scatterplot of FES SUV (on a log scale) and BMI (also logged). Throughout the range of observed BMI, FES SUV is predicted to be higher for higher BMI. This could be due to the known limitations of weight-based SUV [25] or to actual differences in disease characteristics (with respect to estrogen receptor activity) between heavier and lighter women with (mostly) advanced breast cancer. If the effect were due to the weight-based SUV estimation, it should not be evident when uptake is measured by leanbody-mass corrected SUV ( $\mathrm{SUV}_{\mathrm{LBM}}$ ), which attempts to account for the known discrepancy between distribution volume and weight for high BMI patients. Figure 3B shows that no relationship was apparent between FES SUV and BMI when SUV was adjusted for lean body mass using the method of James $(p=0.76)$ [20]. Figure 3C, a scatterplot of corrected and uncorrected FES SUV, illustrates the varying impact of lean body mass correction for individual patients' SUV measures. 
Finally, we explored multivariate models. BMI was still an independent predictive factor in models predicting $\log$ (FES SUV) by SHBG binding and BMI. We explored further

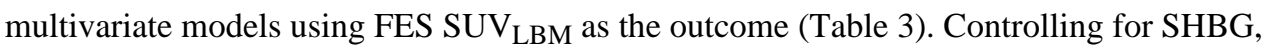
predicting values of $S U V_{L B M}$, no additional predictors were statistically significant. For the full sample ( $\mathrm{n}=284$, excluding scans with no SHBG information), SHBG predicted $\mathrm{SUV}_{\mathrm{LBM}}$ with magnitude comparable to that in the analysis with unadjusted SUV $(\mathrm{p}=0.01)$. For SHBG near the $25^{\text {th }}$ percentile $(31 \mathrm{nM})$, the predicted average $S U V_{L B M}$ was 1.22 , compared to 1.06 at the $75^{\text {th }}$ percentile $(72 \mathrm{nM})$. In the sensitivity analysis dataset, SHBG predicted $\mathrm{SUV}_{\mathrm{LBM}}$ as $5 \%$ lower for a difference in $\operatorname{sqrt}(\mathrm{SHBG})$ of $1.5(\mathrm{p}=0.08)$.

\section{Discussion}

We analyzed biological factors that might influence FES uptake to better understand factors that may contribute to variability of FES uptake measures. We gathered data on these factors for over 300 scans through various FES PET imaging protocols. To screen for factors that might affect uptake, we tested for associations between FES SUV in tumors and several clinical, physical, or chemical factors. Of all the factors tested through univariate analysis, we found that concurrent chemotherapy, BMI, and SHBG had significant association with FES uptake. We also found that plasma estradiol levels and FES catabolism rates did not have a significant association with FES uptake.

For factors related to FES $\mathrm{SA}_{\text {inj }}$, our results indicate that any effect of lower specific activities on FES uptake is quite modest. However, because of a small, though not statistically significant, observed negative relationship between injected FES mass $/ \mathrm{kg}$ and FES SUV for injected mass greater than $0.2 \mathrm{nmole} / \mathrm{kg}$ it seems prudent to limit injected mass to this value. For a typical FES activity dose of $222 \mathrm{MBq}(6 \mathrm{mCi})$ and typical female patient weight of approximately $60 \mathrm{~kg}$, FES SA $\mathrm{inj}_{\text {in }}$ of $18,500 \mathrm{GBq} / \mathrm{mMol}(500 \mathrm{Ci} / \mathrm{mMol})$ or greater, at injection, should not require any dose limitation to reduce mass injected. For $\mathrm{SA}_{\text {inj }}$ less than $18,500 \mathrm{GBq} / \mathrm{mMol}(500 \mathrm{Ci} / \mathrm{mMol})$, and particularly for smaller patients, it may be desirable to reduce the injected activity dose of FES to limit the injected mass.

Fractional FES binding to SHBG and plasma SHBG levels, both indicators of FES binding to SHBG, had a significant association with FES SUV ( $p<0.001$ for both measures). For both SHBG measures the association with FES uptake was inverse, suggesting that higher levels of SHBG binding limit FES uptake at the tumor site. For SHBG at the observed $25^{\text {th }}$ percentile $(31 \mathrm{nM})$, the predicted average $\mathrm{SUV}_{\mathrm{LBM}}$ was 1.22 , compared to 1.06 at the $75^{\text {th }}$ percentile $(72 \mathrm{nM})$. These results show that there is a significant association between SHBG and FES uptake and therefore, SHBG should be measured in each patient. It is also interesting to note that the observed inverse association between SHBG binding and FES uptake is consistent with the free hormone hypothesis which states that the levels of hormone transfer to tissue receptors depends upon the amount of non-bound hormone [26]. On the other hand, prior studies of PET ER imaging agents with poor SHBG binding support that some level of binding is needed for a functional ER imaging agent [14]. Taken together, these observations suggest an optimal range of SHBG binding for PET ER imaging, not surprisingly, at levels close to physiologic levels for estradiol. 
Body mass index appeared to have a significant correlation to FES uptake. The likely explanation for this is that weight overestimates tracer distribution values at higher BMI, resulting in an artifactually high SUV, as has been shown for ${ }^{18} \mathrm{~F}$-Fluorodeoxyglucose (FDG) PET [25, 27, 28]. No relationship was evident when FES SUV values were adjusted for lean body mass rather than weight in $\mathrm{kg}$. When comparing uptake in patients, adjusting for LBM may be helpful to reduce the error associated with tracer distribution.

Equally important in this study to the factors that were significantly associated with FES uptake are some of the factors that were not significantly associated with FES uptake. In our patient group, which included a sizeable number of pre-menopausal patients (33\%), circulating estradiol levels did not appear to effect FES uptake. Looking at pre-menopausal, post-menopausal, and male patients separately, uptake still did not show a significant relationship with estradiol. This finding is consistent with our previous study showing a good correlation between FES uptake and ER expression for both pre- and post-menopausal patients [2], and further implies that ER levels are not saturated by endogenous estradiol in these patients.

Also, the association between the rate of FES catabolism (\%FES) and SUV was not significant. This is consistent with the fact that we did not find an improvement in correlation with in vitro ER assay using FES measures accounting for metabolism, versus for simple uptake measures like SUV [2]. It also allows for simplification in the blood processing by eliminating the need for HPLC analysis of blood samples.

This study has some important limitations. We could not directly adjust for the known effect of tumor ER expression level on FES uptake, but rather tested for associations of factors besides ER expression with uptake in a population with ER-expressing tumors. To reduce the variability of ER expression, we performed sensitivity analysis excluding patients without apparent FES uptake at one or more sites of known and active disease, indicating that ER expression may have been lost. We also observed low uptake in some patients with concurrent chemotherapy and excluded these patients in the sensitivity analysis. Even with these exclusions, the patient population in this analysis was heterogeneous, and the resulting expected variability in FES uptake due to variable ER expression might obscure more subtle associations of some factors with FES uptake. However, the relatively large number of studies provided a means of screening for significant factors that affect FES uptake into tumors.

\section{Conclusion}

Higher SHBG levels and binding correlated with lower FES uptake, and should therefore be measured for each patient. The correlation between BMI and FES SUV uptake suggests a need for LBM correction when comparing SUV values between patients. A non-significant trend was observed suggesting a negative relationship between injected mass $/ \mathrm{kg}$ patient weight and FES uptake at low specific activity. It may therefore be prudent to limit injected dose at lower specific activities for smaller patients. Pre-menopausal levels of estradiol do not appear to affect FES uptake, nor does FES metabolism suggesting that FES metabolism 
may not need to be measured for individual patients. These findings should allow simpler, more targeted protocols for FES imaging in breast cancer patients with ER+ disease.

\section{Acknowledgments}

This work was supported by NIH grants CA42045 (Kenneth Krohn, PI) and CA72064. The authors would like to thank Phil Petra for his expertise in SHBG assays. We also thank the radiochemistry staff, the nuclear medicine technologists and the physicists in the Dept. of Radiology for their assistance with this study.

\section{References}

1. Mintun MA, Welch MJ, Siegel BA, et al. Breast cancer: PET imaging of estrogen receptors. Radiology. 1988; 169:45-8. [PubMed: 3262228]

2. Peterson LM, Mankoff DA, Lawton T, et al. Quantitative imaging of estrogen receptor expression in breast cancer with PET and 18F-fluoroestradiol. J Nucl Med. 2008; 49:367-74. [PubMed: 18287268]

3. Mankoff DA, Link JM, Linden HM, Sundararajan L, Krohn KA. Tumor receptor imaging. J Nucl Med. 2008; 49 (Suppl 2):149S-63S. [PubMed: 18523071]

4. Key TJ. Serum oestradiol and breast cancer risk. Endocr Relat Cancer. 1999; 6:175-80. [PubMed: 10731106]

5. Zeleniuch-Jacquotte A, Toniolo P, Levitz M, et al. Endogenous estrogens and risk of breast cancer by estrogen receptor status: a prospective study in postmenopausal women. Cancer Epidemiol Biomarkers Prev. 1995; 4:857-60. [PubMed: 8634657]

6. Rossi E, Morabito A, Di Rella F, et al. Endocrine effects of adjuvant letrozole compared with tamoxifen in hormone-responsive postmenopausal patients with early breast cancer: the HOBOE trial. J Clin Oncol. 2009; 27:3192-7. [PubMed: 19380451]

7. Katzenellenbogen JA. Designing steroid receptor-based radiotracers to image breast and prostate tumors. J Nucl Med. 1995; 36:8S-13S. [PubMed: 7769466]

8. Katzenellenbogen JA, Welch MJ, Dehdashti F. The development of estrogen and progestin radiopharmaceuticals for imaging breast cancer. Anticancer Res. 1997; 17:1573-6. [PubMed: 9179196]

9. Mathias CJ, Welch MJ, Katzenellenbogen JA, et al. Characterization of the uptake of 16 alpha([18F]fluoro)-17 beta-estradiol in DMBA-induced mammary tumors. Int J Rad Appl Instrum B. 1987; 14:15-25. [PubMed: 3108199]

10. Mankoff DA, Tewson TJ, Eary JF. Analysis of blood clearance and labeled metabolites for the estrogen receptor tracer [F-18]-16 alpha-fluoroestradiol (FES). Nucl Med Biol. 1997; 24:341-8. [PubMed: 9257333]

11. Murad, F. Hormones and hormone antagonists. 8. New York: Pergamon Press; 1990.

12. Kiesewetter DO, Kilbourn MR, Landvatter SW, Heiman DF, Katzenellenbogen JA, Welch MJ. Preparation of four fluorine- 18-labeled estrogens and their selective uptakes in target tissues of immature rats. J Nucl Med. 1984; 25:1212-21. [PubMed: 6092569]

13. Tewson TJ, Mankoff DA, Peterson LM, Woo I, Petra P. Interactions of 16alpha-[18F]fluoroestradiol (FES) with sex steroid binding protein (SBP). Nucl Med Biol. 1999; 26:905-13. [PubMed: 10708304]

14. Jonson SD, Bonasera TA, Dehdashti F, Cristel ME, Katzenellenbogen JA, Welch MJ. Comparative breast tumor imaging and comparative in vitro metabolism of 16alpha-[18F]fluoroestradiol-17beta and 16beta-[18F]fluoromoxestrol in isolated hepatocytes. Nucl Med Biol. 1999; 26:123-30. [PubMed: 10096512]

15. Katzenellenbogen JA, Mathias CJ, VanBrocklin HF, Brodack JW, Welch MJ. Titration of the in vivo uptake of 16 alpha-[18F]fluoroestradiol by target tissues in the rat: competition by tamoxifen, and implications for quantitating estrogen receptors in vivo and the use of animal models in receptor-binding radiopharmaceutical development. Nucl Med Biol. 1993; 20:735-45. [PubMed: 8401374] 
16. Lim JL, Zheng L, Berridge MS, Tewson TJ. The use of 3-methoxymethyl-16 beta, 17 betaepiestriol-O-cyclic sulfone as the precursor in the synthesis of F-18 16 alpha-fluoroestradiol. Nucl Med Biol. 1996; 23:911-5. [PubMed: 8971859]

17. Romer J, Fuchtner F, Steinbach J, Johannsen B. Automated production of 16alpha[18F]fluoroestradiol for breast cancer imaging. Nucl Med Biol. 1999; 26:473-9. [PubMed: 10382853]

18. Linden HM, Stekhova SA, Link JM, et al. Quantitative fluoroestradiol positron emission tomography imaging predicts response to endocrine treatment in breast cancer. J Clin Oncol. 2006; 24:2793-9. [PubMed: 16682724]

19. Fattah DI, Chard T. Simplified method for measuring sex-hormone binding globulin. Clin Chem. 1981; 27:1277-9. [PubMed: 7016374]

20. Hallynck TH, Soep HH, Thomis JA, Boelaert J, Daneels R, Dettli L. Should clearance be normalised to body surface or to lean body mass? Br J Clin Pharmacol. 1981; 11:523-6. [PubMed: 7272167]

21. Cleveland WS. Robust locally weighted regression and smoothing scatterplots. Journal of the American Statistical Association. 1979; 74:829-36.

22. Levine D, Bankier AA, Halpern EF. Submissions to Radiology: Our top 10 list of statistical errors. Radiology. 2009; 253:288-90.

23. Fisher, LD.; van Belle, G. Biostatistics: A methodology for the health sciences. New York: Wiley; 1993.

24. Kuukasjarvi T, Kononen J, Helin H, Holli K, Isola J. Loss of estrogen receptor in recurrent breast cancer is associated with poor response to endocrine therapy. J Clin Oncol. 1996; 14:2584-9. [PubMed: 8823339]

25. Sugawara Y, Zasadny KR, Neuhoff AW, Wahl RL. Reevaluation of the standardized uptake value for FDG: variations with body weight and methods for correction. Radiology. 1999; 213:521-5. [PubMed: 10551235]

26. Hryb DJ, Khan MS, Romas NA, Rosner W. The control of the interaction of sex hormone-binding globulin with its receptor by steroid hormones. J Biol Chem. 1990; 265:6048-54. [PubMed: 2156840]

27. Erselcan T, Turgut B, Dogan D, Ozdemir S. Lean body mass-based standardized uptake value, derived from a predictive equation, might be misleading in PET studies. Eur J Nucl Med Mol Imaging. 2002; 29:1630-8. [PubMed: 12458398]

28. Graham MM, Peterson LM, Hayward RM. Comparison of simplified quantitative analyses of FDG uptake. Nucl Med Biol. 2000; 27:647-55. [PubMed: 11091107] 
A

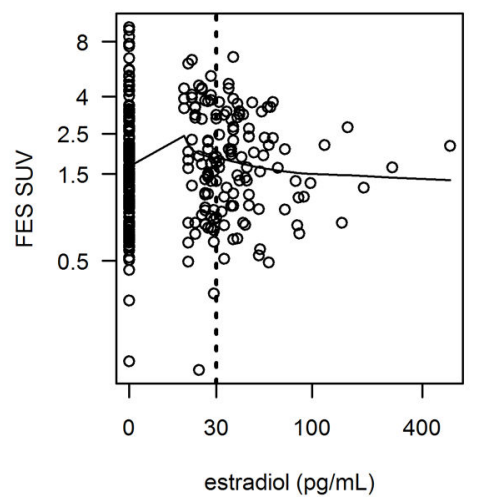

B

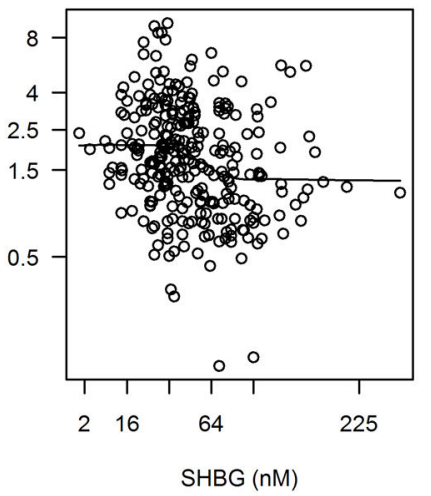

C

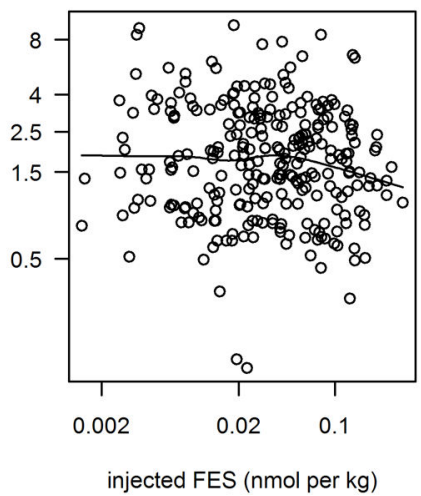

Figure 1.

Scatterplots of $\log ($ FES SUV) plotted against estradiol (A), SHBG binding (B), and injected FES (C). Fitted curves are locally weighted scatterplot smoothing (LOWESS) with smoother span $2 / 3$. 
A

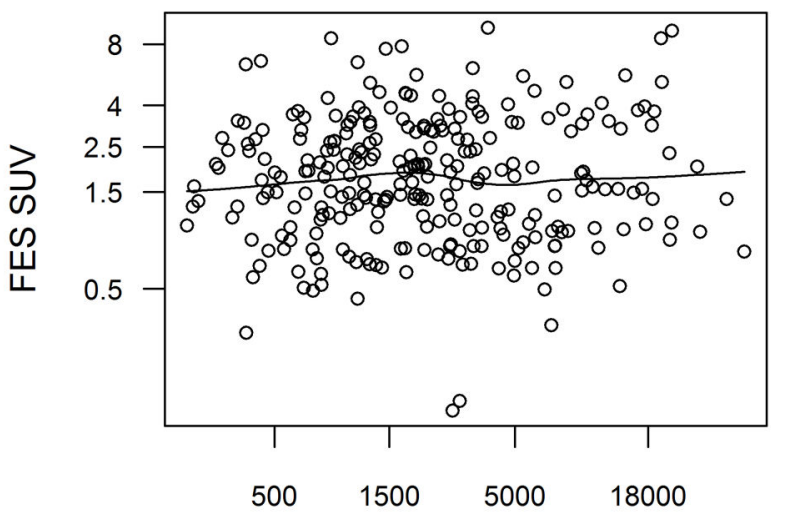

specific activity $(\mathrm{Ci} / \mathrm{mMol})$
B

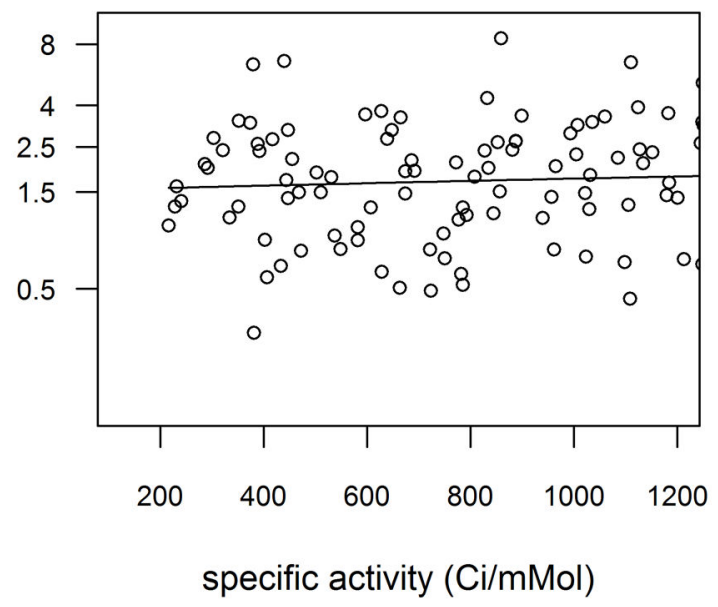

Figure 2.

Scatterplots of $\log$ (FES SUV) plotted against specific activity at time of injection ( $\mathrm{SA}_{\text {inj }}$ ), for all scans (A), and for subset of scans with $\mathrm{SA}_{\mathrm{inj}} \leq 44,400 \mathrm{GBq} / \mathrm{mMol}$ ( $\leq 200 \mathrm{Ci} / \mathrm{mMol}$ ) (B). Fitted curves are locally weighted scatterplot smoothing (LOWESS) with smoother span $2 / 3$. 
A

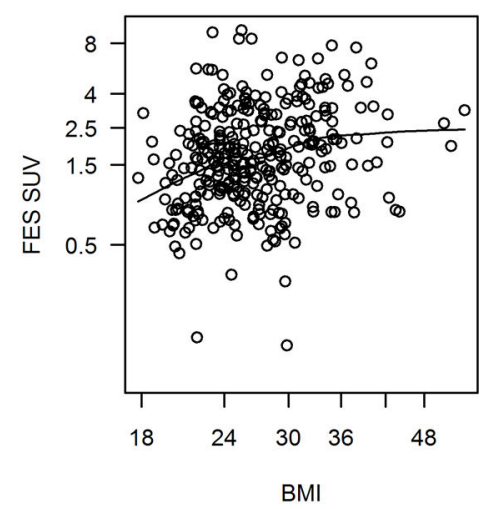

B

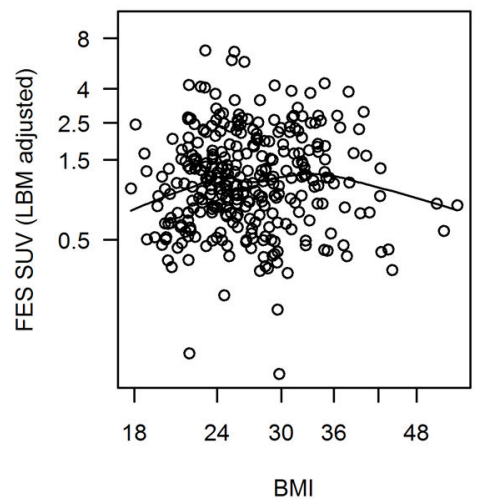

C

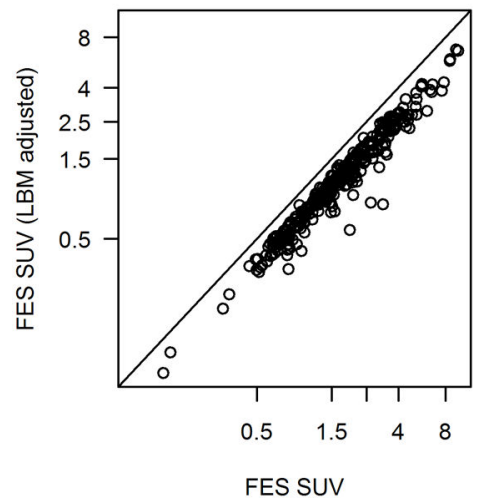

Figure 3.

Exploring the relationship between BMI and FES SUV: $\log ($ FES SUV) plotted against $\log (\mathrm{BMI})(\mathrm{A})$; $\log$ of lean body mass-adjusted FES SUV plotted against $\log (\mathrm{BMI})(\mathrm{B})$; comparison of FES SUV and lean body mass-adjusted FES SUV (C), with line showing equality. Fitted curves are locally weighted scatterplot smoothing (LOWESS) with smoother span $2 / 3$. 
Table 1

Descriptive Characteristics for $\mathrm{N}=312$ FES PET scans in $\mathrm{N}=239$ patients

\begin{tabular}{|c|c|c|c|c|}
\hline & $\begin{array}{c}\mathrm{N} \text { total }(\mathrm{N}=312 \text { if } \\
\text { blank })\end{array}$ & $\begin{array}{c}\mathrm{N} \text { with characteristic } \\
(\% \text { of } \mathrm{N})\end{array}$ & Mean (SD) & Range \\
\hline \multicolumn{5}{|l|}{ Patient Characteristics } \\
\hline Age (years) & & & $54(12)$ & $23-88$ \\
\hline Female sex & & $298(96 \%)$ & & \\
\hline Pre-menopausal (female only) & 298 & $98(33 \%)$ & & \\
\hline Advanced stage breast cancer ${ }^{\dagger}$ & & $298(96 \%)$ & & \\
\hline HER2 positive primary tumor & 293 & $62(21 \%)$ & & \\
\hline Any FES negative sites & 311 & $80(26 \%)$ & & \\
\hline Weight (kg) & & & $74(17)$ & $46-156$ \\
\hline BMI $\left(\mathrm{kg} / \mathrm{m}^{2}\right)$ & & & $27(6)$ & $18-55$ \\
\hline \multicolumn{5}{|l|}{ Prior Treatment } \\
\hline Prior chemotherapy & 298 & $220(74 \%)$ & & \\
\hline Prior radiation & 297 & $170(57 \%)$ & & \\
\hline Prior tamoxifen & 301 & $155(51 \%)$ & & \\
\hline Currently undergoing chemotherapy & 306 & $50(16 \%)$ & & \\
\hline \multicolumn{5}{|l|}{ Blood Assays } \\
\hline Serum Estradiol (pg/mL) & 309 & & $21(43)$ & $0-567$ \\
\hline \multicolumn{5}{|l|}{ Testosterone (ng/mL) } \\
\hline men & 12 & & $3.8(2.8)$ & $0-9.0$ \\
\hline women* & 284 & & $0.3(0.7)$ & $0-9.7$ \\
\hline $\operatorname{Albumin}(\mathrm{g} / \mathrm{dL})$ & 280 & & $3.6(0.4)$ & $2.3-5.1$ \\
\hline Serum SHBG (nM) & 284 & & $55(37)$ & $3-287$ \\
\hline FES metabolism (\%at $20 \mathrm{~min})^{* *}$ & 278 & & $29(13)$ & $4-83$ \\
\hline \multicolumn{5}{|l|}{ FES Characteristics for Imaging } \\
\hline FES specific activity at injection $(\mathrm{GBq} / \mathrm{mMol})$ & 267 & & $156,917(228,068)$ & $7992-1,671,216$ \\
\hline FES injected Activity dose (MBq) & & & $185.0(25.9)$ & $103.6-296$ \\
\hline FES injected per patient weight (nmol/kg) & 267 & & $0.05(0.05)$ & $0.001-0.31$ \\
\hline SHBG Binding (\%FES bound to SHBG) & 293 & & $32(15)$ & $0-66$ \\
\hline
\end{tabular}

${ }^{\dagger}$ Advanced Stage Breast cancer refers to Stage III or IV.

$8 \%(23 / 284)$ of women had testosterone levels $>0.7 \mathrm{ng} / \mathrm{mL}$

Percent of total blood activity present as FES at 20 minutes after injection determined by HPLC 


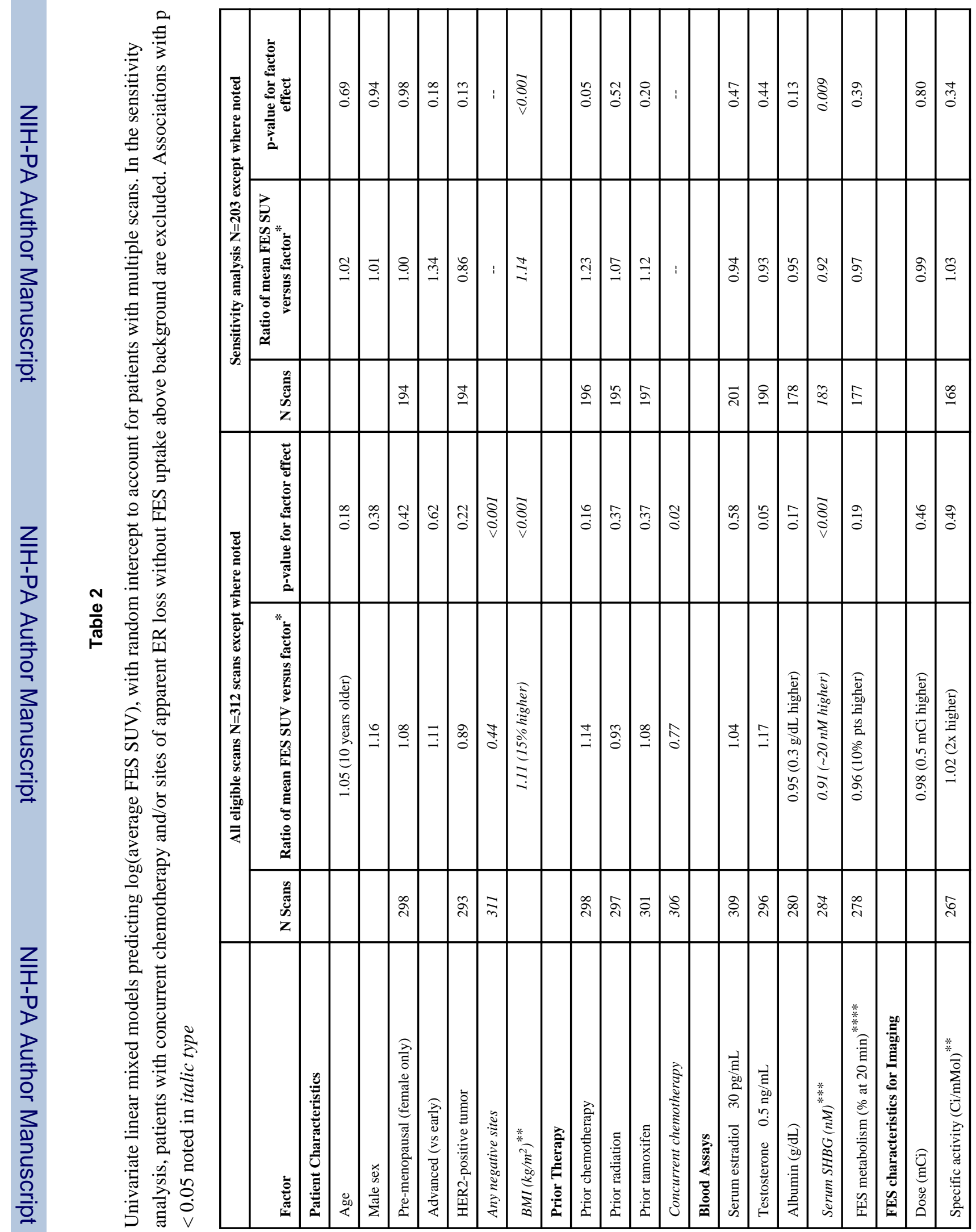




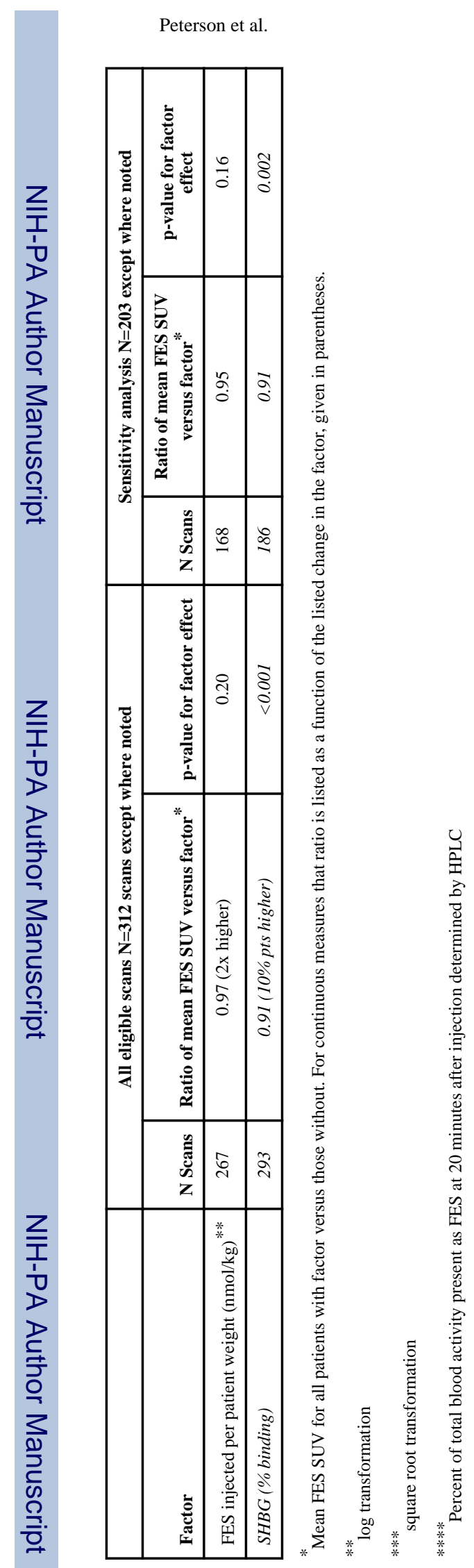

Nucl Med Biol. Author manuscript; available in PMC 2014 July 23. 


\section{Table 3}

Linear mixed model with the square root of SHBG predicting $\log ($ lean body mass-adjusted FES SUV), with random intercept to account for patients with multiple scans. In the sensitivity analysis, patients with concurrent chemotherapy and/or sites of apparent ER loss without FES uptake above background are excluded

\begin{tabular}{|l|l|c|l|c|}
\hline & Patients with SHBG analysis N=284 & p-value & $\begin{array}{l}\text { Sensitivity analysis of patients who had SHBG } \\
\text { analysis N=183 scans }\end{array}$ & p-value \\
\hline SHBG $(\mathrm{nM})^{* * *}$ & $\begin{array}{l}\text { predicted SUV } \mathrm{LBM}_{\text {L }} \text { 7\% lower when } \\
\text { difference in sqrt(SHBG) is } 1.5\end{array}$ & 0.01 & $\begin{array}{l}\text { predicted SUV } \\
\text { sqrt(SHBG) is } 1.5\end{array}$ & 0.08 \\
\hline
\end{tabular}

